thrombus is a logical extension of this theme and is now being practised. ${ }^{18-21}$

Intracoronary thrombolysis during myocardial infarction must be attempted very soon after formation of the thrombus. This immediately poses problems such as the diagnosis of infarction at this stage and the increased risk of coronary arteriography. The urgency also limits the application of the technique because the number of partients within quick reach of a coronary care unit with facilities for emergency investigation is likely to be small, at least in Britain. Nevertheless, infusion of streptokinase started within a few hours of the onset of symptoms can restore arterial patency within 20 minutes or so, and further improvement may occur with longer periods of infusion ${ }^{21}$; lysis may be helped by passing a guide wire through the thrombus. ${ }^{18}{ }^{20}$ The procedure is not without risk, the most common complications being ventricular arrhythmias and formation of a haematoma at the site of the femoral artery puncture. In the relatively small series reported so far arterial patency has been restored in about threequarters of patients. But does this help? Probably it does. Myocardial perfusion assessed by thallium scintigraphy improves immediately ${ }^{21}$; pain may be relieved and raised electrocardiographic ST segments abolished ${ }^{18}$; left ventricular function assessed by radionuclide angiography does not change immediately but is better by the time of discharge from hospital in those patients whose arteries are recanalised as compared with those whose arteries remain blocked. ${ }^{20}$ The numbers treated so far are too small to permit any comment on survival.

So we now have two methods of unblocking coronary arteries. Intracoronary streptokinase in acute myocardial infarction is still being evaluated, but seems to confirm the role of thrombosis in this disease. It is likely to have limited application in Britain and certainly should not be regarded as a reason for equipping every district general hospital with facilities for coronary arteriography. Those hospitals with such facilities should certainly be trying it in selected cases. Percutaneous transluminal coronary angioplasty is better established and has a definite place in the management of patients with stable angina pectoris; indications for its use may grow.

\section{C Petch}

Consultant Cardiologist,

Papworth Hospital,

Cambridge CB3 8RE

${ }^{1}$ De Wood MA, Spores J, Notske R, et al. Prevalence of total coronary occlusion during the early hours of transmural myocardial infarction. $N$ Engl f Med $1980 ; 303: 897-902$.

${ }^{2}$ Sones FM Jr, Shirley EK, Proudfit WL, Westcott RN. Cine-coronary arteriography. Circulation 1959;20:773-4.

${ }^{3}$ Dotter CT, Judkins MP. Transluminal treatment of arteriosclerotic obstruction. Description of new technique and a preliminary report of its application. Circulation $1964 ; 30: 654-70$.

4 Grüntzig A. Transluminal dilatation of coronary-artery stenosis. Lancet $1978 ; \mathrm{i}: 263$.

${ }^{5}$ Block PC, Myler RK, Stertzer S, Fallon JT. Morphology after transluminal angioplasty in human beings. N Engl f Med 1981 ;305:382-5.

${ }^{6}$ Levy RI, Mock MB, Willman VL, Passamani ER, Frommer PL. Percutaneous transluminal coronary angioplasty-a status report. $N$ Engl f Med $1981 ; 305: 399-400$.

${ }^{7}$ Hamby RI, Katz S. Percutaneous transluminal coronary angioplasty: its potential impact on surgery for coronary artery disease. Am $\mathcal{F}$ Cardiol $1980 ; 45: 1161-6$.

${ }^{8}$ Grüntzig A. Percutaneous transluminal angioplasty. AfR 1981 ;136:216-7.

- Bourassa MG. Percutaneous transluminal coronary angioplasty-still an investigational procedure. Mayo Clin Proc 1981 ;56:334-5.

${ }^{10}$ Meyer J, Schmitz H-J, Erbel R, Kiesslich T, Messmer B, Effert S. Comparison of transluminal coronary angioplasty in unstable and in stable angina pectoris. Circulation $1981 ; 64$, suppl $4:$ IV-79. (Abstract.)

11 McCallister BD, Hartzler GO, Rutherford BD, McConahay DR. Pal- liative percutaneous transluminal coronary angioplasty for unstable angina in patients over 70 years of age. Circulation $1981 ; 64$, part II IV-255. (Abstract.)

12 Block PC, Palacios IF, Wholey MH, O'Toole J. Percutaneous transluminal angioplasty of stenotic coronary artery bypass grafts. Circulation 1981 ; 64, part II :IV-109. (Abstract.)

${ }^{13}$ Kannel WB, Feinleib $M$. Natural history of angina pectoris in the Framingham study. Prognosis and survival. Am 7 Cardiol 1972;29: 154-63.

${ }^{14}$ Davies MJ, Woolf N, Robertson WB. Pathology of acute myocardial infarction with particular reference to occlusive coronary thrombi. Br Heart 7 1976;38:659-64.

${ }^{15}$ Hjalmarson $\AA$, Herlitz J, Malek I, et al. Effect on mortality of metoprolol in acute myocardial infarction. Lancet 1981 ;ii:823-6, 7.

16 Yusuf S, Petro R, Bennett D, et al. Early intravenous atenolol treatment in suspected acute myocardial infarction. Lancet 1980;ii:273-6.

${ }^{17}$ European Cooperative Study Group for Streptokinase Treatment in Acute Myocardial Infarction. Streptokinase in acute myocardial infarction. N Engl f Med 1979;301:797-802.

${ }^{18}$ Rentrop P, Blanke H, Karsh KR, Kaiser H, Kostering H, Leitz K. Selective intracoronary thrombolysis in acute myocardial infarction and unstable angina pectoris. Circulation $1981 ; 63: 307-17$.

${ }^{19}$ Mathey DG, Kuck K-H, Tilsner V, Krebber H-J, Bleifeld W. Nonsurgical coronary artery recanalization in acute transmural myocardial infarction. Circulation $1981 ; 63: 489-97$.

${ }^{20}$ Reduto LA, Smalling RW, Freund GC, Gould KL. Intracoronary infusion of streptokinase in patients with acute myocardial infarction: effects of reperfusion on left ventricular performance. Am $\mathcal{F} \mathrm{Cardiol}$ $1981 ; 48: 403-9$.

${ }^{21}$ Markis JE, Malagold M, Parker JA, et al. Myocardial salvage after intracoronary thrombolysis with streptokinase in acute myocardial infarction. Assessment by intracoronary thallium-201. N Engl f Med $1981 ; 305$ : 777-82.

\section{Gastric cancer}

Gastric cancer is three times ${ }^{1}$ more common in Japan than in Britain, and patients present there at a younger age. ${ }^{2}$ The proportion of all gastric cancers classified as "early" has increased in Japan to over $30 \%,{ }^{3}$ while in Europe it ranges from $0.3 \%{ }^{4}$ or more ${ }^{56}$ up to $10 \%$ or $11 \%$, with the highest incidence in specialist centres. ${ }^{7}$ Excellent five-year survival figures are reported from Japan compared with results from Europe, North America, and Australia. The results need careful interpretation, however, with close attention to the recognition of early gastric cancer, the staging of advanced cancer, ${ }^{8}$ and histological classification. One factor that contributes to the high incidence of early gastric cancer in Japan is screening. Experience with multiphasic cancer screening and investigation of patients having symptoms in Italy ${ }^{10}$ has shown, however, that the numbers of early gastric cancers detected are in line with the reported incidence in Western countries.

The detection rate of early gastric cancer depends on the endoscopist, who should first take specimens by brush cytology and then at least five biopsy specimens from suspicious gastric lesions. ${ }^{11}$ The incidence of detected premalignant lesions and early gastric cancer may be increased if particular attention is paid to high-risk groups such as patients with pernicious anaemia, chronic atrophic diffuse gastritis accompanied by achlorhydria or hypochlorhydria, those who have had a gastrectomy or gastroenterostomy, and those with adenomatous polyps or Menetrier's disease. Radiologists also make a very important contribution to the detection of early gastric cancer, and the value of double-contrast studies cannot be overemphasised.

Recent studies on tests for tumour markers in gastric juice have generated interest. Correlations have been reported between lactate dehydrogenase and $\beta$-glucuronidase activi- 
ties $^{12}$; and these correlations and the screening programme based on fetal sialoglycoprotein antigen ${ }^{13}$ were claimed to contribute to the detection of early gastric cancer, though false-positive results did occur. Cytophotometry ${ }^{14}$ has also been used for screening purposes.

The pathologist plays a crucial part in identifying and classifying gastric cancers and assessing lesions. Endoscopic biopsies require careful assessment for the recognition of nonmalignant lesions such as gastritis and peptic ulcer, and particularly for the diagnosis of malignant or potentially malignant lesions, which include adenomatous polyps, severe dysplasia, intramucosal carcinoma, and invasive carcinoma. Criteria ${ }^{15}$ have been elaborated to differentiate between these lesions, but they are subjective rather than quantitative and depend on the experience of the pathologist. Differences in interpretation do occur-which ought to encourage the search for clearer definitions, acceptable internationally, of the cytological features and architectural abnormalities constituting these lesions. The nomenclature used by pathologists and the significance of these lesions must be clearly understood by clinicians. For example, evaluating incomplete intestinal metaplasia type $2 \mathrm{~B}$ as a premalignant lesion ${ }^{16-18}$ and as a predictor of gastric cancer requires prospective and retrospective analysis, since it may possibly represent an associated lesion only. The endoscopic classification of early gastric cancer $^{19}$ introduced by the Japanese is, however, generally accepted.

Pathologists should recognise their responsibility for accurate classification of the lesions in surgically resected specimens, which should be sent to the pathology department fresh and unopened so that the specimen can be pinned out, fixed, and examined with great care. Inconspicuous areas of early gastric cancer are easily overlooked in specimens of gastric and duodenal ulcers if this procedure is not followed. The number of histological blocks sampled will vary with the discretion of the pathologist, but centres with a special interest carry out very detailed studies. Assessment of the lymph nodes depends on co-operation between the surgeon and pathologist.

The histological classification ${ }^{20}$ of gastric cancer has become increasingly complex, but the one most widely used in epidemiological studies is that of Laurén, ${ }^{21}$ which differentiates between intestinal and diffuse carcinoma. The intestinal type accounts for the high prevalence in Japan. A recent review of the biological behaviour of gastric cancer in a Japanese necropsy series $^{22}$ uses a more complicated system based on three main groups-namely, adenocarcinoma, mucoid carcinoma, and diffuse carcinoma, with a total of nine subgroups. The material was chosen from a consecutive series of 294 patients with gastric cancer examined post mortem in whom only conservative treatment had been given or in whom cancer was first diagnosed at necropsy. The histological studies are detailed and comprehensive.

This study confirms that well-differentiated adenocarcinoma occurs predominantly in elderly men and that poorly differentiated adenocarcinoma occurs predominantly in young men. Well-differentiated adenocarcinoma has a better prognosis after surgical resection. The authors devised a metastatic index based on the number, distribution, and histological type of metastases. Tumours with a high metastatic index included poorly differentiated adenocarcinoma, poorly differentiated mucoid carcinoma, and anaplastic diffuse carcinoma; while those with a low metastatic index were classified as welldifferentiated and moderately differentiated adenocarcinoma, solid medullary adenocarcinoma, and well-differentiated mucoid carcinoma.
Cancers in the group with a low metastatic index spread to the liver much more often than those with a high index. There was a high incidence of liver metastases in carcinoma of the pylorus and in cancer extending to the whole of the stomach. In confirmation of earlier reports, well-differentiated mucoid carcinoma ${ }^{23}$ was found to be a relatively restrained tumour with regard to the number and distribution of its metastases. These observations will be important for all engaged in the study of gastric cancer and for all pathologists who seek prognostic markers.

\section{H THOMPSON}

Consultant Pathologist

General Hospital,

Birmingham $\mathrm{B} 46 \mathrm{NH}$

${ }^{1}$ Segi M, Kuihara N. Cancer mortality for selected sites in 24 countries. No 4 (1962-63). Sendai : Japan Cancer Society, Department of Public Health, Tohoka University, School of Medicine, 1966.

${ }^{2}$ Kubo T. Geographical pathology of gastric carcinoma. Acta Pathol fpn $1974 ; 24: 465-79$.

3 Takagi K. The incidence of early gastric cancer since the advant of endoscopy. In: Fielding JWL, Newman CE, Ford CHJ, Jones BG, eds. Gastric cancer. Oxford: Pergamon Press, 1981:159-68. (Advances in the Biosciences. Vol 32.)

4 Miller G, Froelicher P. Early gastric cancer in Europe. Cotton PB, ed. Proceedings of second BSG/SKF international workshop on early gastric cancer, 1981. Welwyn Garden City: Smith Kline and French. (In press.)

5 Fielding JWL, Ellis DJ, Jones BG, et al. Natural history of "early" gastric cancer: results of a 10-year regional survey. Br Med f 1980;281:965-7.

${ }^{6}$ Holdstock G, Bruce S. Endoscopy and gastric cancer. Gut 1981 ;22:673-6.

7 Johansen AA. Early gastric cancer in current topics in pathology. In: Morson BC, ed. Pathology of the gastro-intestinal tract. Vol 3. Berlin: Springer-Verlag, 1976:1-47.

${ }^{8}$ Craven JL. International variation in the results of treatment of gastric cancer. In: Fielding JWL, Newman CE, Ford CHJ, Jones BG, eds. Gastric cancer. Oxford: Pergamon Press, 1981:219-29. (Advances in the Biosciences. Vol 32.)

9 Aste HD, Amadori G, Maltoni G, et al. Early gastric cancer detection in four areas at different gastric cancer death rate. Acta Endoscopica 1981; $11: 123-32$.

${ }^{10}$ Crespi M. Mass screening for stomach cancer-Europe. In: Cotton PB, ed. Proceedings of second BSG/SKF international workshop on early gastric cancer, 1981. Welwyn Garden City: Smith Kline and French. (In press.)

${ }^{11}$ Keighley MRB, Thompson H, Moore J, Hoare AM, Allan RN, Dykes PW. Comparison of brush cytology before or after biopsy for diagnosis of gastric carcinoma. Brf Surg 1979;66:246-7.

12 Rogers K, Roberts GM, Williams GT. Gastric-juice enzymes-an aid in the diagnosis of gastric cancer. Lancet 1981 ; :1124-6.

${ }^{13}$ Hakkinen I. Application of serum and gastric juice tumour markers to early diagnosis and screening of gastric cancer. In: Fielding JWL, Newman CE, Ford CHJ, Jones BG, eds. Gastric cancer. Oxford: Pergamon Press, 1981:85-92. (Advances in the Biosciences. Vol 32.)

14 Witte $S$. Current procedures of the early detection of gastric cancer. In: Varrō V, Balint GA, eds. Current views in gastroenterology. Vol 1. Budapest : Hungarian Society of Gastroenterology, 1977:485-91.

15 Morson BC, Sobin LH, Gundmann E, Johansen A, Nagayo T, Hanssen AS. Precancerous conditions and epithelial dysplasia in the stomach. $\mathcal{f}$ Clin Pathol 1980;33:711-21.

16 Jass JR, Filipe MI. Sulphomucins and precancerous lesions of the human stomach. Histopathology $1980 ; 4: 271-9$.

${ }^{17} \mathrm{Jass} \mathrm{JR}$. Role of intestinal metaplasia in the histogenesis of gastric carcinoma. F Clin Pathol $1980 ; 33: 801-10$.

18 Matsukura N, Suzuki K, Kawachi $\mathrm{T}$, et al. Distribution of marker enzymes and mucin in intestinal metaplasia in human stomach and relation of complete and incomplete types of intestinal metaplasia to minute gastric carcinomas. $¥ N C I$ 1980;65:231-40.

19 Murakami T. Pathomorphological diagnosis. Definition and gross clarification of early gastric cancer. In: Murakami T, ed. Early gastric cancer. Tokyo: University of Tokyo Press, 1972:53-5. (Gann Monograph on Cancer Research. No 11.)

${ }^{20}$ Day DN. Histopathology of gastric cancer. In: Fielding JWL, Newman $\mathrm{CE}$, Ford CHJ, Jones BG, eds. Gastric cancer. Oxford: Pergamon Press, 1981 :98-109. (Advances in the Biosciences. Vol 32.)

${ }^{21}$ Laurén P. The two histological main types of gastric carcinoma: diffuse and so-called intestinal-type. An attempt at a histo-clinical classification. Acta Pathol Microbiol Scand 1965;64:31-49.

${ }^{22}$ Ishii $\mathrm{T}$, Ikegami N, Hosoda $\mathrm{Y}$, Koide O, Kaneko $\mathrm{M}$. The biological behaviour of gastric cancer. $\mathcal{F}$ Pathol 1981;134:97-115.

${ }^{23}$ Brander WL, Needham PRG, Morgan AD. Indolent mucoid carcinoma of stomach. $\mathcal{f}$ Clin Pathol 1974 ;27:536-41. 